\title{
Empirical valuation of road and roadside environment considering heterogeneous preferences
}

\author{
S. Mizokami ${ }^{1} \&$ M. Parumog ${ }^{2}$ \\ ${ }^{I}$ Department of Civil and Environmental Engineering, \\ Kumamoto University, Japan \\ ${ }^{2}$ Graduate School of Science and Technology, \\ Kumamoto University, Japan
}

\begin{abstract}
Stated choice experiments eliciting willingness-to-pay (WTP) for environmental goods and services provide the means to assign monetary estimates to the social and environmental costs of motor-vehicle use such as air pollution, noise and congestion. However, fixed parameter models indicating homogeneous WTP estimate dominates current applications. This paper investigates the need to account for heterogeneity in the WTP estimates of stated preference models involving an internet-based survey on the valuation of road and roadside environment in Metro Manila. Initially, factors affecting heterogeneity in WTP are investigated using contingent valuation $(\mathrm{CV})$ data. Then, random parameter choice models are estimated to describe the effects of preference heterogeneity in attribute-based valuation data. Finally, the implications of value estimates on environmental policies for Metro Manila are presented.

Keywords: environmental valuation, heterogeneity, random coefficient model.
\end{abstract}

\section{Introduction}

Mobility improvements still play a vital role in the economic growth of many developing nations. However, high motorization rates as a consequence of increased mobility is triggering unaccounted environmental costs, such as air pollution, noise, congestion, accidents, and urban decay. In developing countries, concentration of total suspended particulate, recently linked with respiratory and cardiac diseases, is found to be many times higher than the World Health 
Organization (WHO) guideline of $90 \mu \mathrm{g} / \mathrm{m}^{3}$ [1]. Transport related noise, which projected to grow proportionally with the rapid growth of number of motor vehicles, poses environmental concerns. Moreover, the WHO reported that 20 million people are severely injured or killed each year in traffic related accidents, most of which are from developing countries [2]. This picture calls for valuation of the social and environmental costs of travel that are necessary to evaluate alternative transport policies, or basis of implementation mechanisms for pricing strategies, Pigovian taxes, and vehicle regulations.

In Metro Manila, the social and environmental costs of motorization are considerably extensive. Above $40 \%$ of all registered vehicles in the Philippines are in Metro Manila. These motor vehicles are making about 17.5 million trips a day [3]. This figure is still increasing and implying greater environmental stress to the network. Ambient air and noise standards, for instance, are exceeded in many areas in the city. In a 2001 preliminary assessment of outdoor air pollution and health in Metro Manila conducted by University of the Philippines, the average annual total suspended particulate (TSP) is $153 \mu \mathrm{g} / \mathrm{m}^{3}$, more than two times the standard. Moreover, the noise standard of 80 decibels is exceeded even in some residential areas.

The need to incorporate full social costs of traffic in urban management policies has been considered by many researchers and policy-makers in recent years. In the United States and Europe, reports presenting methods and estimates of social costs of motor vehicle have been comprehensively done $[4,5]$. In Metro Manila, a number of studies have been made to measure social costs of traffic in Metro Manila. In 2003, ADB sponsored a research on market-based instruments to evaluate air pollution control policy options [6]. Roth and Villoria [7] measured social cost of congestion and proposed a congestion charge in the range of 6 to 14 Philippine peso (PHP) per passenger car unit per km to increase travel speed by 44 to $101 \%$. Premature deaths from PM10 was estimated to range from 0.5 to 14.3 billion PHP in 1992 [8]. Fabian and Vergel [9] estimated an average 1.24 PHP WTP to equip diesel exhaust of jeepneys with particulate trap. Most of these studies are based on market-based estimation methods.

Contingent valuation method (CVM) and stated choice (SC) tasks dominate the existing non-market valuation studies. Valuation of non-monetary social costs has become one of rather recent applications of the well-developed random utility choice models using stated preference (SP) data [10-13]. These are commonly estimated using the versatile multinomial logit model [14]. Recent advancement in computing have rendered the estimation of complex discrete choices with mixed distribution probabilistic assumptions possible though simulations [15].

This paper aims to make three contributions. Firstly, to investigate factors influencing heterogeneity in WTP for environmental amenities to examine the need for random parameter models, secondly, to investigate diversions in estimate of fixed and the random parameter models and, lastly, to contribute to the limited literature on valuation of non-monetary motor-vehicle use in developing countries. The $\mathrm{CV}$ data used consist of the double-bounded 
dichotomous format WTP for improvements in road and roadside environmental attributes for public and private work commuters. On the other hand, in the estimation of the random parameters model, we used the SC route choice data from private work trips.

\section{The choice experiment}

This paper uses data from internet-based stated-choice survey employing two methods, a CV and an SC experiment, to obtain estimates of WTP for road and roadside environmental improvements in noise, air quality, and road safety. The questionnaire has five parts: work trip characteristics; environmental quality perception in commonly used route; environmental attitudes; the experimental choice problems; the CV WTP elicitations and the socioeconomic characteristics of respondents. In the CV questions, the respondents were asked of their WTP for extreme improvements in road and roadside environments using referendum $\mathrm{CV}$ format with follow-up. The payment vehicle for the private trips is additional payments in fuel and registration taxes while for public trips, fare increase is offered.

In the SP route choice experiment, we looked into attributes corresponding to non-monetary environmental costs of transport such as noise and air pollution. Furthermore, variables travel time and risk reductions from traffic accidents are added in the choice dimensions. Travel time is generally classified as personal non-monetary costs. Risk value of a traffic fatality, on the other hand, is agued to encompass both external, as in lost and suffering incurred by victims, and internal costs, as traveller himself or herself makes the decision to travel or not to travel [16]. A screen shot of the SC route choice problem is shown in Figure 1.

\begin{tabular}{|c|c|c|c|}
\hline Route attributes & $\begin{array}{c}\text { Current } \\
\text { Route }\end{array}$ & $\begin{array}{c}\text { Route } \\
\text { Alternative } 1\end{array}$ & $\begin{array}{c}\text { Route } \\
\text { Alternative 2 }\end{array}$ \\
\hline (1) Total travel time from home to office (in minutes) & 20 mins. & 21 mins. & 13 mins. \\
\hline Fotal travel cost from home to office (in pesos) & P30 & P58 & P36 \\
\hline Percent in air quality improvement & - & $80 \%$ & $50 \%$ \\
\hline Ai) Percent in traffic noise reduction & - & $80 \%$ & $20 \%$ \\
\hline S Greenery and landscape improvement & - & $\begin{array}{l}\text { greenery and } \\
\text { streetscape } \\
\text { improvements }\end{array}$ & no improvements \\
\hline خ Average number of road fatalities per year & 150 & 25 & 75 \\
\hline $\begin{array}{l}\text { If you can still choose your current alternative what will be } \\
\text { your choice among the three alternatives? }\end{array}$ & c & c & c \\
\hline $\begin{array}{l}\text { If you are to choose only among the new alternatives, which } \\
\text { route will you take? }\end{array}$ & & c & o \\
\hline Cont inue page 7 of 15 & & & \\
\hline
\end{tabular}

Figure 1: $\quad$ SP route choice experiment.

Attribute levels are randomly varied using html embedded scripts. The survey was conducted among employees in Metro Manila conducted from June 5 to July $1,2005$. 


\section{Factors affecting heterogeneity of WTP}

This section discusses the factors that are likely to influence variance of the observed variable WTP and the actual mode choice, i.e. private or public, using path analysis. The details of the questions for the different measures investigated here are presented in Table 1. Attitude (ATT) is measured using three behavioural statements deemed to closely correspond to altruistic, responsible and moral behaviours of individuals. Bipolar rating (agree-disagree) on situational statements were elicited from respondents to indicate attitudes. Perception (PER) relates to how respondent perceive his or her most familiar route and his or her perception on how the government is doing their job on its maintenance. Five-item bipolar scales on perception of environmental conditions are used. Road and roadside environment perception measured are air pollution (poor-good), noise annoyance (extremely-slightly), greenery and streetscape (poor-good) and road safety (dangerous-safe). Revealed preference (RP) represents the actual mode used by the respondents which are encoded as dummy, 0 for private and 1 for public. $W T P$ is the probability the respondent pay the mean of the computed WTP normal distribution using double-bounded referendum CV questions. Socioeconomic variables (SOC) uses for the purpose of this application are employment type, number of years in school, and monthly income. Structural equation modelling using LISREL [17] model was done to estimate parameters of assumed path structure. Some 259 observations are used for the estimation.

Table 1: $\quad$ Structural equation variables.

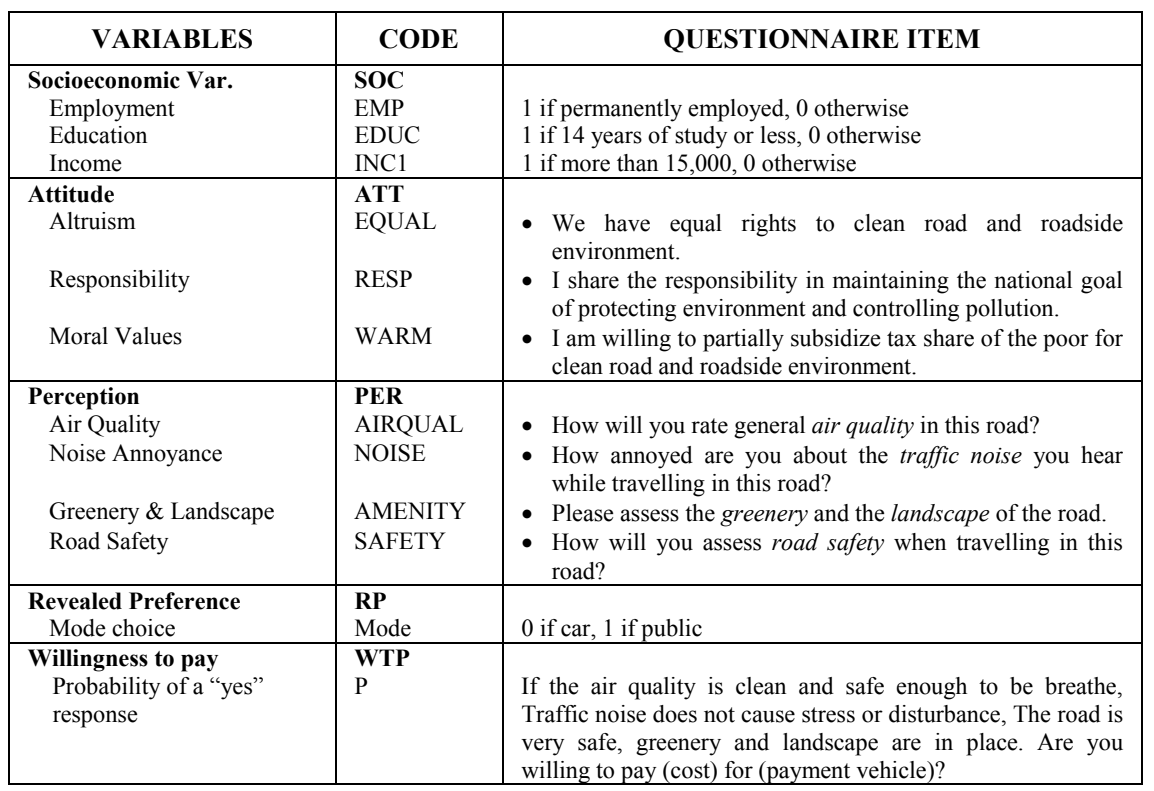


The standardized estimate of the parameters of the structural equation model is shown in Figure 2. The statistical fit of the model is relatively acceptable at ML $\chi^{2}$ is 79.43 with $\mathrm{df}=44$, p-level is 0.00085 , and RMSEA 0.055 . In the structure, three latent exogenous variables, attitude (ATT), perception (PER), socioeconomic characteristics (SOC), and an endogenous latent variable mode choice (MODE) are introduced to directly affect the observed WTP of the respondents. Error correlation structures among the latent exogenous variables are likewise assumed. Only the error correlation between PER and ATT with a negative parameter and a significance level of about $10 \%$ appears to be noteworthy. This indicates that as perception of the environmental quality worsens, the attitude of the respondents towards the environment is likewise impaired. Among the four latent variables assumed to directly influence WTP, $\mathrm{RP}$ is found have the most notable positive effect at $1 \%$ level of significance followed by ATT with a positive effect of about $5 \%$ level of significance.

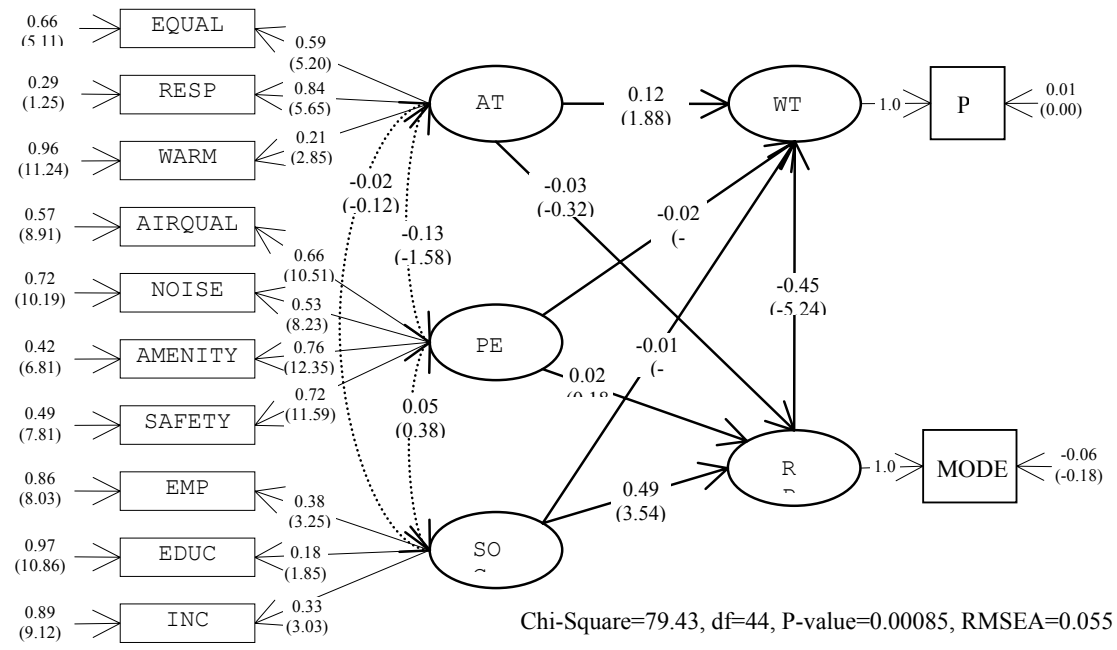

Figure 2: $\quad$ Estimate of variables affecting WTP.

The results of the estimation of assumed path structure show that, while it is a common knowledge that socioeconomic characteristics are the main cause of heterogeneity in stated WTP, its effect are only indirect. Revealed preference, which may be a function of socioeconomic characteristics, is more likely to influence stated WTP based on the empirical data presented here. It is also noteworthy that the attitude latent variable poses relatively significant influence on WTP. Various researches have shown similar effect of preferences and attitudinal variables in WTP $[18,19]$.

\section{Random coefficient model and WTP}

This section presents the estimation of discrete random parameter models to account for heterogeneity in the WTP estimates of road and roadside 
environmental improvement as an effect of the actual preferences and attitudes as presented in the previous section.

\subsection{Model specifications}

Route choice utility depends on the route characteristics or attributes, a function of the explanatory variables and the stochastic or random part of utility. Route attributes can be classified into the objective attributes, travel time and travel cost, and subjective attributes such as like environmental quality, safety, and view. In the analysis here, we define the utility as:

$$
U_{j}=\sum_{M} \beta_{M} x_{M j}+\beta_{p} x_{p j}+\sum_{s=1}^{S} \beta_{s} x_{s j}+\varepsilon_{j}
$$

where $x_{M j}$ stands for the different route alternative $j$ attributes, $x_{p i}$ is the cost, $x_{s j}$ are other explanatory variables, $\beta$ are the associated utility parameter and $\varepsilon_{j}$ is the random unmeasured utility components. In this utility specification, attributes are assume to be independent of each other, meaning preference over one attribute do not affect other attributes preference, and, thus, follow simple additive relationship.

Assuming effects of attributes are captured in deterministic part, WTP indicator in this choice problem can be described by ratio of the marginal utilities with respect to environmental attribute and price. In a simple linear specification of utility, the value of a unit of air pollution reduction can then be computed from the ratio of and attribute coefficient $\beta_{M}$ which is the particular attribute parameter and cost coefficient $\beta_{p}$, respectively.

However, environmental amenities, just like any subjective attribute in the stated choice question, are complex concepts that vary according to individual. The difference in how an individual realize degree of alternative's attributes weight like congestion or presence of pollution causes parameters of discrete choice structural equations to follow certain distribution. We have shown previously that attitudes and revealed preferences have an effect on stated WTP to these amenities. To determine effect of heterogeneity in choice models incorporating taste heterogeneity, we investigated only main effects parameters in the choice experiment in Figure 1.

$$
V_{j}=\alpha_{j}+\beta_{1} x_{\text {time }}+\beta_{2} x_{\text {air }}+\beta_{3} x_{\text {noise }}+\beta_{4} x_{\text {acc }}+\beta_{p} x_{p}+\varepsilon_{j}
$$

Since heterogeneity in WTP is established to be influenced by preferences and attitudes in the empirical data used in this study, is not likely for the estimated coefficients to be fixed or common across observations. To consider this, we estimate a mixed logit model where not only stochastic part of the indirect utility, but also alternative attribute coefficients, varies randomly. We assume that $\beta$ follows a continuous normal distribution the choice probability is defined as: 


$$
P=\int\left(\frac{e^{V_{j}}}{\sum_{j} e^{V_{j}}}\right) \phi\left(\beta \mid b, \sigma^{2}\right) d \beta
$$

where $\phi\left(\beta \mid \mathrm{b}, \sigma^{2}\right)$ is a normal density with mean $\mathrm{b}$ and variance $\sigma^{2}$. This can be estimated by maximum simulated likelihood discussed in Train [15].

\subsection{Estimation results}

Table 2 shows estimate of the fixed parameter model (MNL) and the normally distributed random parameter models with all parameters distributed (MMNL) and in an alternate model where the cost parameter is held fix (MMNLFC). The models were estimated using a non-commercial estimation package BIOGEME [20]. In the random parameter models, 1000 pseudo random draws to approximate probability are employed.

Table 2: $\quad$ Parameter and WTP estimates.

\begin{tabular}{|c|c|c|c|}
\hline Parameter & MNL & MMNL & MMNL-FC \\
\hline$\alpha_{2}$ & $2.204(4.49)$ & $4.351(1.49)$ & $2.944(2.33)$ \\
\hline$\alpha_{3}$ & $2.020(4.04)$ & $4.225(1.36)$ & $2.802(2.17)$ \\
\hline$\beta_{\mathrm{p}}($ Travel cost $)$ & $-0.009(-3.60)$ & $-0.019(-1.19)$ & $-0.014(-1.88)$ \\
\hline$\sigma_{\mathrm{p}}$ & & $0.003(0.28)$ & \\
\hline$\beta_{1}$ (Travel time) & $-0.041(-4.79)$ & $-0.100(-1.68)$ & $-0.079(-2.18)$ \\
\hline$\sigma_{1}$ & & $0.103(1.88)$ & $0.078(1.44)$ \\
\hline$\beta_{2}$ (Air pollution) & $-0.499(-1.21)$ & $-1.883(-1.37)$ & $-0.869(-1.24)$ \\
\hline$\sigma_{2}$ & & $1.372(1.04)$ & $1.448(0.51)$ \\
\hline$\beta_{3}$ (Noise) & $-0.550(-1.42)$ & $-1.414(-1.21)$ & $-0.892(-1.31)$ \\
\hline$\sigma_{3}$ & & $1.861(0.29)$ & $1.653(0.83)$ \\
\hline$\beta_{4}$ (Traffic fatalities per year) & $-0.010(-4.21)$ & $-0.019(-1.69)$ & $-0.016(-2.11)$ \\
\hline$\sigma_{4}$ & & $0.024(0.89)$ & $0.013(0.83)$ \\
\hline Goodness of fit index & & & \\
\hline No. of observation & 221 & 221 & 221 \\
\hline$\chi^{2}$ statistic (p-level) & $80.07 \quad(0.0000)$ & $83.09(0.0000)$ & $85.15(0.0000)$ \\
\hline Adjusted $\rho^{2}$ & 0.136 & 0.122 & 0.130 \\
\hline WTP point estimates for: & & & \\
\hline Time (in minutes) & $4.41 \quad$ (3.13) & $5.13(2.40)$ & $5.54(2.78)$ \\
\hline $100 \%$ air pollution reduction & $53.93 \quad(1.19)$ & $96.60(2.45)$ & $61.03(1.43)$ \\
\hline $100 \%$ noise reduction & $59.45 \quad(1.39)$ & $72.54(2.07)$ & $62.69(1.59)$ \\
\hline Avoiding a traffic death in a year & $1.10 \quad(1.74)$ & $0.97(2.18)$ & $1.10(2.67)$ \\
\hline
\end{tabular}

The goodness of fit indices of the three models is almost equally acceptable. The statistical significance of the WTP estimates presented here are computed using mean estimators' variances. The point estimates of WTP may increase or decrease based on specifications of the marginal utilities.

Figure 3 shows the cumulative distribution function (CDF) of the coefficient estimate of the MMNL model. From the figure, the tendency of some of the parameters (i.e. travel time, air quality, noise) to have positive values in some part of the distribution can be seen. The wide variance of the coefficient of air 
quality and noise can also be observed indicating significant perception heterogeneity for the variable. This indicates that some respondents are indifferent to air and noise quality improvements. As expected, respondents have more certain preferences for variables of personal character than that of the subjective, environmental nature. If we relate this with the previous SE models, it can be roughly deduced that attitudinal factors affect subjective variables such as non-use environmental resources more than use or personal resources.

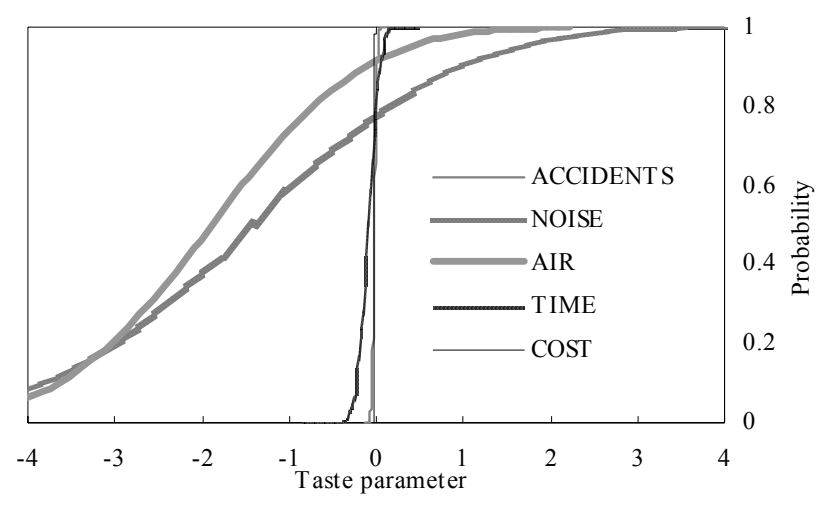

Figure 3: $\quad$ CDF of parameter estimates from MMNL.

\subsection{Policy implications for Metro Manila}

The finding that the attitudinal character of individuals, correlated to his or her perceptions of environmental quality, has significant influence to WTP is a matter that must be considered in planning. The practice of improving peoples' perception through impact projects to perk up approval ratings of politicians has been a common practice in developing countries. This system, while unsustainable in some infrastructure project, may be a considerable option for environmental improvement projects. In terms of transport policies, though subjectivity and heterogeneity of environmental attributes such as noise and air pollution is very strong among road users, one might actually control it by controlling or altering latent variables such as attitudes and perceptions. This can be done by policies such as marketing strategies, information campaign, training and counselling.

The value of estimates from MMNLFC is used here for simpler model interpretations. We first adjusted the estimated mean WTP based on the actual income structure in Metro Manila. The income adjusted value for WTP are 10.22 PHP for $100 \%$ air improvement, 10.50 PHP for 100\% improvement in noise, 0.18 PHP to avoid risk of 1 in 100 traffic fatalities in a year, and 0.93 PHP value of travel time savings per minute. These values can be used in evaluating nonmonetary external cost to road users in evaluation of alternative policy schemes. For instance, the WTP for fine particulate traps fitted in diesel vehicles' exhaust which are found to cut PM10 emission to about 20\%, can be estimated to amount 
to 2 PHP. Based on the WTP estimate to avoid traffic fatality, on the other hand, value of statistical life (VSL) for reducing 1 in 100 fatal accident in a year considering mean estimate is $4.8 \mathrm{M}$ PHP can be used for transport policy evaluation. The previous estimates above are based on the point estimates, if we consider the spread of the coefficient estimates, values, particularly for air and noise improvement, may even have negative values in some segments of the population.

\section{Summary and conclusions}

In this paper, we have shown the need to consider heterogeneity in environmental valuation model to better estimate WTP for road and roadside environmental attributes in an empirical application in Metro Manila. We have shown based on structural equation model that preferences, as a function of socioeconomic variables, and attitudes influences heterogeneity in values for environmental amenities. We likewise present that, random parameter choice models can account for this heterogeneity. Based on the empirical application done, we found that non-use goods or attributes like noise and air quality is more prone to heterogeneity than other direct or indirect use goods or attributes like time and risks from accidents. It can be deduced from here that preferences and attitudes have more influence on stated WTP for non-use resources. This finding necessitates the use of models accounting for heterogeneity in environmental valuation studies. The WTP estimates in random parameter models are useful for various transport and environmental policy in Metro Manila.

In the estimations, random parameter model may account for the heterogeneity but interpretation of the models in terms of latent variables such as attitudes and perception is limited. As an alternative, other models such as latent variable discrete choice models may be used and investigated.

\section{References}

[1] Beyond Economic Growth: Meeting the Challenges of Global Development, IADB and The World Bank: Washington, D.C., 2000.

[2] Neglected Global Epidemics: three growing threats, The World Health Report, The World Health Organization: Geneva, 2003.

[3] Metro Manila Urban Transportation Integration Study, JICA, 1998.

[4] Murphy, J. \& M. A. Delucchi, Review of some of the literature on the social cost of motor-vehicle use, Institute of Transportation Studies University of California: Davis, Calif., 1996.

[5] Rennings, K., O. Hohmeyer \& R. L. Ottinger, Social costs and sustainable mobility: strategies and experiences in Europe and the United States, Physica-Verlag Heidelberg, New York, and Mannheim, 2000.

[6] Krupnick, A., R. Morgenstern, C. Fisher, K. Rolfe, J. Logarta \& B. Rufo, Air Pollution Control Policy Options for Metro Manila, Resources for the Future: Washington D.C., 2003. 
[7] Roth, G. \& O. Villoria, Jr., Finances of Commercialized Urban Road Network Subject to Congestion Pricing, Transportation Research Record, (1747), 2004.

[8] Larssen, S., F. Gram, L. O. Hagen, H. Jansen, X. Olsthoorn, R. Lesaca, E. Anglo, E. B. Torres, R. D. Subida \& H. A. Fransisco, Urban Air Quality Management Strategy in Asia (URBAIR), in J. Shah\& T. Nagpal, eds, International Bank of Reconstruction and Development/ The World Bank: Washington D.C., 1996.

[9] Fabian, H. G. \& K. N. Vergel, Analysis of Air Pollution Exposure of Individuals in the Road Environment, Journal of the Eastern Asia Society for Transportation Studies, 4(5), pp. 55-70, 2001.

[10] Arsenio, E., A. L. Bristow \& M. Wardman, Stated choice valuations of traffic related noise, Transportation Research Part D: Transport and Environment, 11(1), pp. 15-31 2006.

[11] Iraguen, P. \& J. de Dios Ortuzar, Willingness-to-pay for reducing fatal accident risk in urban areas: an Internet-based Web page stated preference survey, Accident Analysis \& Prevention, 36(4), pp. 513-524, 2004.

[12] Wardman, M. \& A. L. Bristow, Traffic related noise and air quality valuations: evidence from stated preference residential choice model, Transportation Research Part D, 9, pp. 1-27, 2004.

[13] Saelensminde, K., Stated choice valuation of urban traffic air pollution and noise, Transportation Research Part D: Transport and Environment, 4(1), pp. 13-27, 1999.

[14] McFadden, D., Conditional logit analysis of qualitative choice behavior, Frontiers of Econometrics, P. Zarembka, ed., Academic Press, 1974.

[15] Train, K., Discrete choice methods with simulation, Cambridge University Press: New York, 2003.

[16] Schreyer, C., C. Schneider, M. Maibach, W. Rothengatter, C. Doll \& D. Schmedding, External Cost of Transport - An Update, INFRAS/IWW: Zurich, 2004.

[17] LISREL: online documentation, http://www.ssicentral.com/lisrel/.

[18] Kotchen, M. J. \& S. D. Reiling, Environmental attitudes, motivations, and contingent valuation of nonuse values: a case study involving endangered species, Ecological Economics, 32(1), pp. 93-107, 2000.

[19] Milon, J. W. \& D. Scrogin, Latent preferences and valuation of wetland ecosystem restoration, Ecological Economics, In Press, Corrected Proof.

[20] Bierlaire, M., BIOGEME: a free package for the estimation of discrete choice models, Proceedings of the 3rd Swiss Transport Research Conference: Monte Verita, Ascona, Switzerland, 2003. 